\title{
BMJ Global Health Tuberculosis preventive treatment: the next chapter of tuberculosis elimination in India
}

Patrick K Moonan, ${ }^{1}$ Sreenivas A Nair, ${ }^{2}$ Reshu Agarwal, ${ }^{3}$ Vineet K Chadha, ${ }^{4}$ Puneet K Dewan, ${ }^{5}$ Umesh D Gupta, ${ }^{6}$ Christine S Ho, ${ }^{3}$ Timothy H Holtz, ${ }^{3}$ Ajay M Kumar, ${ }^{7}$ Nishant Kumar, ${ }^{8}$ Prahlad Kumar, ${ }^{9}$ Susan A Maloney, ${ }^{1}$ Sundari R Mase, ${ }^{10}$ John E Oeltmann, ${ }^{1}$ C N Paramasivan, ${ }^{11}$ Malik M Parmar, ${ }^{12}$ Kiran K Rade, ${ }^{12}$ Ranjani Ramachandran, ${ }^{12}$ Raghuram Rao, ${ }^{8}$ Virendra S Salhorta, ${ }^{8}$ Rohit Sarin, ${ }^{13}$ Sanjay Sarin, ${ }^{11}$ Kuldeep S Sachdeva, ${ }^{8}$ Sriram Selvaraju, ${ }^{14}$ Rupak Singla, ${ }^{15}$ Diya Surie, ${ }^{1}$ Jamhoih Tonsing, ${ }^{16}$ Srikanth P Tripathy, ${ }^{17}$ Sunil D Khaparde ${ }^{8}$

To cite: Moonan PK, Nair SA, Agarwal R, et al. Tuberculosis preventive treatment: the next chapter of tuberculosis elimination in India. BMJ Glob Health 2018;3:e001135. doi:10.1136/ bmjgh-2018-001135

Handling editor Alberto L Garcia-Basteiro

PKM and SAN contributed equally.

Received 22 August 2018 Revised 10 September 2018 Accepted 11 September 2018

Check for updates

(c) Author(s) (or their employer(s)) 2018. Re-use permitted under CC BY-NC. No commercial re-use. See rights and permissions. Published by BMJ.

For numbered affiliations see end of article.

Correspondence to Dr Patrick K Moonan; pmoonan@cdc.gov

\section{ABSTRACT}

The End TB Strategy envisions a world free of tuberculosis-zero deaths, disease and suffering due to tuberculosis by 2035 . This requires reducing the global tuberculosis incidence from $>1250$ cases per million people to $<100$ cases per million people within the next two decades. Expanding testing and treatment of tuberculosis infection is critical to achieving this goal. In high-burden countries, like India, the implementation of tuberculosis preventive treatment (TPT) remains a low priority. In this analysis article, we explore potential challenges and solutions of implementing TPT in India. The next chapter in tuberculosis elimination in India will require cost-effective and sustainable interventions aimed at tuberculosis infection. This will require constant innovation, locally driven solutions to address the diverse and dynamic tuberculosis epidemiology and persistent programme monitoring and evaluation. As new tools, regimens and approaches emerge, midcourse adjustments to policy and practice must be adopted. The development and implementation of new tools and strategies will call for close collaboration between local, national and international partners - both public and private-national health authorities, non-governmental organisations, research community and the diagnostic and pharmaceutical industry. Leading by example, India can contribute to global knowledge through operational research and programmatic implementation for combating tuberculosis infection.

\section{INTRODUCTION}

In 2014, the World Health Assembly set global targets for tuberculosis (TB) prevention, care and control, ${ }^{1}$ serving as the impetus for the End TB Strategy. ${ }^{2}$ This ambitious strategy envisions ' $a$ world free of tuberculosis-zero deaths, disease, and suffering due to tuberculosis' by $2035 .{ }^{2} \mathrm{~TB}$ elimination requires reducing

\section{Summary box}

An estimated 354 million people are latently infected with tuberculosis in India and form the next generation of future tuberculosis cases.

- TB preventive treatment (TPT) can reduce rates of progression from infection to active TB disease by $90 \%$. Yet in many high-burden countries, like India the implementation of TPT remains a low priority, is underused and often avoided in practice.

- TPT will play a major role in bending the epidemiologic curve in India and will require constant innovation, locally-driven solutions, and persistent programme monitoring and evaluation.

- Leading by example, India can contribute to global knowledge of TPT through research and programmatic implementation.

the global TB incidence from $>1250$ cases per million people to $<100$ cases per million people within the next two decades. ${ }^{3}$ The WHO developed a framework for low-incidence countries for achieving tuberculosis elimination. ${ }^{4}$ This framework focused on several key tenets: systems strengthening (eg, political commitment, funding, surveillance, programme monitoring and evaluation), accelerating case detection and ensuring efficacious treatment (eg, relapse-free cure and preventing the acquisition of drug resistance) and preventing future cases (eg, reducing transmission, infection control, contact tracing, testing and treatment of tuberculosis infection and vaccination). ${ }^{4}$ It was hoped that the lessons learnt in low-incidence countries could be translated to high-burden countries. ${ }^{5}$ This may not be effective, as experiences in Australia, Europe and North 
America are likely different, given the epidemiology of tuberculosis is driven by immigration and large number of cases attributed to reactivation of tuberculosis infection. ${ }^{6-8}$ Moreover, some key interventions being planned in high-resource areas may not be practical to implement elsewhere without substantial investment and additional human resources.

\section{Bending the epidemiological curve}

The path to global tuberculosis elimination is based on mathematical modelling. ${ }^{9}$ The WHO predicts that optimising current tools (eg, rapid molecular diagnostics, modifying current treatment regimens to increase adherence) and improvements in universal access to health coverage will reduce the annual incidence rate of $\mathrm{TB}$ by $10 \%$ per year by $2025 .{ }^{9}$ However, the steepest rate of decline is expected with introduction of new drugs and treatment regimens for active TB, tuberculosis preventive treatment (TPT) and ultimately-an effective vaccine to prevent TB infection or activation to TB disease. ${ }^{9}$ Until then, it is up to TB control programmes to design interventions to best identify and treat the estimated 1.7 billion people worldwide that are latently infected with TB and form the next generation of future tuberculosis cases. ${ }^{10}$ Planning for this next era of tuberculosis prevention in high-burden countries-that is, increased focus on diagnosis and treatment of tuberculosis infection-needs to happen now, rather than later, if we are to achieve our global targets.

\section{Rationale for targeted testing and treatment of tuberculosis infection}

The concept of TPT began more than half a century ago. ${ }^{11-13}$ During 1957-1977, aggressive community-wide implementation of TPT in the Yukon-Kuskowim River delta of Alaska reduced TB incidence by $17 \%$ per annum ${ }^{1415}$-a rate similar to the targeted declines needed today to reach global elimination. Several well-designed clinical trials have since validated several regimens as an effective and safe way to prevent future TB disease. ${ }^{16} 17$ The benefit of preventing individuals from progressing to active TB, especially persons at high risk of reactivation, is widely accepted. ${ }^{18}$ Available treatment, when taken appropriately, can reduce rates of progression from infection to active disease by $90 \%{ }^{18}$ Yet in many high-burden countries, like India, the implementation of TPT remains a low priority, is underused, and often avoided in practice. ${ }^{19}$

\section{Challenge 1-Burden}

India has an estimated annual tuberculosis incidence of 2170 cases per million people. ${ }^{20}$ The top priority for the Revised National Tuberculosis Programme, India (RNTCP) is to detect, treat and monitor people with active TB disease. This is an enormous task. In 2016, 1.7 million TB cases reported to the government, ${ }^{20}$ an estimated 2.2 million cases were presumed to have received care in the largely unregulated private sector. ${ }^{21} 22$ Several key strategies have been outlined in the RNTCP National Strategic Plan 2017-2025 (NSP) to address this burden. ${ }^{23}$ If this plan is funded and executed appropriately, ${ }^{22}$ India is poised to make substantial progress towards finding missing cases more quickly, ensuring universal drug susceptibility testing, implementing the most efficacious regimen, ensuring treatment adherence and monitoring relapse through surveillance. However, recent models suggest that focus on TB disease alone has a limited impact on the reduction in future incidence without the additive effect of TPT. ${ }^{24}$ Assuming a conservative average of four household contacts per case and $50 \%$ tuberculosis infection rate among them, ${ }^{25-31}$ an estimated 4 million new tuberculosis household infections occur in India every year. Without further action and investment, 28 million new tuberculosis household infections will occur by 2025 (table 1). Many millions more will also emerge from the

Table 1 Potential burden of latent tuberculosis infection among household members by antituberculosis drug resistance profile, India-2016

\begin{tabular}{|c|c|c|c|}
\hline & $\begin{array}{l}\text { Proportion with DST } \\
\text { profile }\end{array}$ & $\begin{array}{l}\text { Estimated number of TB index } \\
\text { cases }\end{array}$ & $\begin{array}{l}\text { Estimated number of household } \\
\text { tuberculosis infections }\end{array}$ \\
\hline DST result & n (95\% confidence limits) ${ }^{\star}$ & n (95\% Cl)† & $\mathrm{n}(95 \% \mathrm{Cl}) \neq \S$ \\
\hline Drug susceptible & 72.0 (70.7 to 73.2$)$ & 1263569 (1 240755 to 1284629$)$ & 3032566 (2977 812 to 3083110$)$ \\
\hline Any resistance to isoniazid & 11.1 (10.3 to 12.4$)$ & 194800 (180 761 to 217615$)$ & 467520 (433 826 to 522 276) \\
\hline Any resistance to rifampicin & 6.2 (5.5 to 6.9$)$ & 108807 (96 523 to 121092$)$ & 261137 (261 137 to 290621$)$ \\
\hline $\begin{array}{l}\text { Any resistance to } \\
\text { fluoroquinolone }\end{array}$ & 5.1 (4.5 to 5.8$)$ & 89503 (78 973 to 101788$)$ & 214807 (189 535 to 244291 ) \\
\hline Total & & & 3 976030 (3 862310 to 4140298 ) \\
\hline
\end{tabular}

*Source data: Ministry of Health and Family Welfare. Government of India. Report of the first nationwide antituberculosis drug resistance survey-India, 2014-2015. ${ }^{70}$

†Revised National Tuberculosis Control Programme Case Reporting Data, 2016. N=1754 957.30

$\ddagger$ Office of the Registrar General and Census Commissioner, India. HH-01. Normal Households by Household Size. Mean household size $=4.8 .^{31}$

§Assumes 50\% latent tuberculosis infection rate. ${ }^{10}$ 25-29

DST, drug susceptibility testing. 
huge reservoir of an estimated 354 million people previously infected with tuberculosis in India. ${ }^{10}$

\section{Challenge 2-Identifying persons for tuberculosis preventive treatment}

In practice, TPT in India is based on ruling out active disease (as opposed to detecting infection) and then offering prophylaxis to those without active disease among high-risk populations, such as children aged $<6$ years and persons living with HIV. Expanding TPT in India will require a frameshift in the design and implementation of contact tracing activities and also the more regular use of diagnostic tests for tuberculosis infection. It is worth noting that the positive predictive value of all current diagnostic tests for tuberculosis infection are dependent on the pretest probability of progressing to disease. ${ }^{32}{ }^{33}$ It is neither practical nor appropriate to conduct wholesale testing in the general population. The vast majority of persons with tuberculosis infection will never progress to active tuberculosis disease. ${ }^{18} 33$ Testing for tuberculosis infection with the current tools, among persons who are otherwise healthy and have low risk of progressing to disease, would be low yield, and incur a high implementation cost. Therefore, rational, evidencebased, targeted testing would be a more appropriate and cost-effective strategy.

Accordingly, the NSP calls for prioritising screening for tuberculosis infection among people living with HIV, paediatric contacts of sputum-smear positive index cases, and persons with clinically indicated risk (eg, persons receiving long-term immune-suppressants, corticosteroid use, diabetes mellitus, silicosis, and the undernourished). ${ }^{23}$ Indeed these groups are at high-risk of progressing to disease, but two additional important groups should also be considered: all household contacts (regardless of age) and healthcare workers at greatest risk of exposure to patients with infectious TB. India must transition from ruling out active disease to detecting tuberculosis infection, from passive screening that places responsibility on the patient and household member to present for care, to actively screening contacts at places and times convenient to them. ${ }^{34}$ In addition, the current strategy for screening healthcare workers focuses on finding active disease. Preventing tuberculosis infection among healthcare workers will require two important components-improved airborne infection control in all health facilities as well as actively screening and treating tuberculosis infection-including periodic surveillance for new tuberculosis infection (suggesting recent transmission) among healthcare workers. It should be emphasised that while TPT will offer some reduction in risk of progression to disease, the risk of repeat exposure and subsequent reinfection will remain high, lowering the yield of preventive efforts, unless all aspects of airborne infection control (ie, administrative measures, environmental controls and the routine use of personal respiratory-protection equipment) ${ }^{3536}$ and contact tracing are implemented effectively. ${ }^{37}$ The recently endorsed F-A-S-T strategy (Finding TB cases Actively, Separating safely and Treating effectively) may prove useful in implementing TB airborne infection control throughout the Indian healthcare system. ${ }^{38}$

\section{Challenge 3-Development and adoption of new diagnostic tools}

India has been slow to adopt recent technologies to diagnose tuberculosis infection. As a national policy, RNTCP relies on the tuberculin skin test (TST) to detect infection. ${ }^{39}$ The TST has several limitations. Poor reproducibility, with inter-reader and intrareader variability in measurement, the requirement of two patient visits separated by 48 to 72 hours, and high false-positive rate among persons who received bacillis Calmette-Guérin (BCG) vaccination have been reported. ${ }^{40}$ Interferon-gamma release assays (IGRAs) offer some advantages over the TST, but these are also imperfect tests. ${ }^{41}$ IGRAs appear to have greater specificity than TST in BCG-vaccinated populations. ${ }^{42}$ Despite the in vitro design and standardisation protocols for IGRA, substantial variability in test reproducibility has been reported. ${ }^{41}{ }^{43-47}$ Product cost, technical complexity and limited commercial availability of IGRA cast doubt to whether IGRA-based screening strategies are more cost effective than TST-based strategies in high-burden settings. ${ }^{48}$ To further complicate matters, WHO and the RNCTP banned the use of serological testing (eg, tests for antibodies $\operatorname{IgA}, \operatorname{IgG}$, IgM) as diagnostic tools for tuberculosis disease. ${ }^{50} 51$ This ban may have caused confusion in the utility of blood-based IGRAs for detecting tuberculosis infection, especially in the private sector. ${ }^{52}$ Also, there is a persistent shortage of quality-assured purified protein derivative (PPD), the substance used during TST. ${ }^{53}$ The unstable supply of quality-assured PPD has likely resulted in fewer persons tested and increased use of alternative diagnostic products of dubious quality. Further operational research is needed to optimise the diagnosis of tuberculosis infection. Establishing which test, if any, is the most appropriate test to use in India is a top priority. There is an urgent need for a reliable, cost-effective test to rapidly detect tuberculosis infection and identify those most likely to benefit from preventive treatment.

\section{Challenge 4-Tuberculosis preventive treatment acceptance, adherence and completion}

The initiation and adherence to TPT has been historically poor. ${ }^{54-61}$ This may be a result of lack of general awareness and perceived risk, ${ }^{566061}$ non-availability of standard tuberculin product, ${ }^{56}{ }^{59}$ drug stock-outs (including pyridoxine) ${ }^{57} 58$ limited access to radiography (to exclude TB disease),${ }^{56-59}$ long duration of therapy (in absence of symptoms) and poor programmatic monitoring. ${ }^{54} 56-60$ Moreover, in India, the practice of TPT is predominately for children. ${ }^{39-59}$ In the few studies that enrolled adult participants, TPT acceptance rates were exceptionally low $(17 \%)^{61}$ or treatment was not offered because of perceived high background tuberculosis infection 
prevalence, risk of repeated exposure and reinfection, risk of drug toxicity and concerns of widespread isoniazid monoresistance in India. ${ }^{60} 61$ All of these concerns are relevant. The risk of drug intolerance and severe toxicity, although worrisome, were infrequent in other settings, and appear to be age-associated, or found among persons with other risk factors for hepatotoxicity (eg, excessive alcohol use). ${ }^{16}{ }^{62-64}$ In some high-prevalence TB settings, where the risk of reinfection is high, studies have demonstrated benefit of preventive treatment with longer durations. ${ }^{6566}$ A study from Chennai found that both 6-month and 36-month isoniazid preventive treatment regimens among HIV-infected persons was equivalent in safety, tolerance and effectiveness. ${ }^{67}$ The optimal length of TPT in India remains unknown (eg, extended duration regimens to cover reinfection vs shorter adherence-friendly regimens) and is likely subject to feasibility and other logistical considerations. High rates of treatment completion $(87 \%)$ were recently reported in routine practice using a 12-dose weekly isoniazid and rifapentine regimen (3HP) in a low-prevalence country. ${ }^{68}$ This treatment holds promise to improve acceptance and adherence to TPT worldwide; ${ }^{69}$ however, the efficacy of $3 \mathrm{HP}$ among populations with a high prevalence of drug resistance remains unknown. Indeed, drug resistance in India is also a concern. The recent nationally representative antituberculosis drug resistance survey found that $11 \%$ of new and $25 \%$ previously treated patients had a form of isoniazid-resistant tuberculosis. ${ }^{70}$ These results, when extrapolated to estimated number of new household contacts with tuberculosis infection, suggest that millions of persons every year may not benefit from the various regimens designed to halt the progression from infection to active forms of drug-resistant tuberculosis (table 1). Unfortunately, there is no diagnostic test that can assess the drug susceptibility profile of any given infection (non-active $\mathrm{TB}$ ), and there are no published randomised clinical trials for the treatment of tuberculosis infection caused by isoniazid-resistant or multidrug-resistant (MDR) forms of tuberculosis. ${ }^{16}$ However, several alternative preventive regimens are available. ${ }^{16}$ Contacts of patients with isoniazid-monoresistant TB have been successfully treated with rifampicin-based regimens ${ }^{72} 73$ and support the current recommendations to use 4 months of daily rifampicin under certain conditions. ${ }^{16}{ }^{71}$ Among MDR TB contacts, fluoroquinolone-based preventive treatment may be considered ${ }^{74}$ global treatment guidelines are forthcoming, ${ }^{75}$ but further research is needed prior to wide-scale use, ${ }^{76}$ - especially in India where overconsumption $^{77}$ and uncontrolled use of fluoroquinolones has been reported. ${ }^{78-80}$ It is unclear which TPT regimen would be most effective in India. We must establish which TPT regimens are most effective in India, with careful consideration of posology and duration for children and adults. Notwithstanding, all persons offered TPT must be thoroughly evaluated to rule out active disease, assessed to select an appropriate treatment course (including careful review of potential exclusion conditions) and closely monitored for the development of treatment-related adverse events and poor adherence.

\section{Way forward}

Given the above burden and challenges, expanding the identification and treatment of tuberculosis infection in India might seem overwhelming and unachievable. However, incremental progress towards elimination is possible with careful evidence-guided policy development, planning and implementation. ${ }^{81}$ Table 2 describes the major challenges to implementing treatment of tuberculosis infection in India, and highlight potential solutions.

Multinational political will and leadership is warranted to finance our ambitious global TB elimination efforts. The identification, testing and monitoring of TPT will require substantial increases in the number of programme personnel, training and education for healthcare providers and patients, diagnostic and drug procurement (ie, TST, IGRA, pyridoxine, rifapentine), resources to build and expand diagnostic and laboratory capacity and surveillance mechanisms. It is critical to ensure that TPT initiatives do not divert resources from essential and expanding commitments devoted to persons with TB disease. Wide-scale implementation is not advisable without sufficient resources to ensure that most patients complete the full cascade of TPT.

Tuberculosis in India is very heterogeneous, both from an epidemiological perspective and in terms of programmatic performance. Results from subnational tuberculosis prevalence surveys (ie, active disease), ${ }^{82-87}$ subnational and district-level annual rate of tuberculosis infection surveys ${ }^{88}$ and analysis of routinely collected programme surveillance data ${ }^{54} 89$ reveal substantial local variation in tuberculosis incidence, tuberculosis prevalence, rates of HIV coinfection, drug-resistant forms of $\mathrm{TB}$ and utilisation of $\mathrm{TB}$ services in the private sector. There are enormous epidemiological and programmatic differences between urban and rural areas. For example, urban areas are characterised by lower tuberculosis prevalence but higher annual risk of tuberculosis infection, while rural areas are characterised by higher tuberculosis prevalence and lower annual risk of tuberculosis infection. ${ }^{88} 89$ Thus, the design of effective, targeted, TPT interventions cannot be 'one-size-fits-all', but rather tailored to local epidemiology and programme performance. For example, ruling out active tuberculosis disease, an essential component of TPT, is particularly challenging in remote areas that do not have access to radiography or qualified personnel for interpreting radiography and experience logistic issues with transporting sputa over long distances (ie, non-viable and contaminated specimens). Initiating single-drug TPT for patients with active tuberculosis could result in acquired resistance and further prolong infectiousness. ${ }^{92}$ Simple, easy-to-use algorithms for determining TPT eligibility, appropriate regimen and length of treatment should be 
Table 2 Potential challenges and solutions to tuberculosis preventive treatment implementation, India

\begin{tabular}{ll}
\hline Major challenges & Potential solutions \\
\hline Political will and leadership & Unprecedented attention to the urgent global response to end tuberculosis. United Nations \\
& General Assembly meeting will take place in September, $2018^{\star}$ \\
& Prime Minister Narendra Modi pledges to eliminate TB by 2025 in India (10 years in advance of \\
& global targets) † \\
& Leveraging the international community to negotiate 'patient-friendly' pricing for newer drugs, \\
& especially for low income families suffering from TB
\end{tabular}

Ability to rule-out TB disease

Adopting international screening algorithms to the local context (with and without chest radiographs) $\ddagger$

Availability and use of Xpert MTB/RIF testing (Cepheid, Sunnyvale, California, USA)§

Availability and use of chest radiography. India has a robust health system; however, access to care is asymmetrical between rural and urban populations. The forthcoming 'Ayushman Bharat Yojana' (National Health Protection Mission) $\uparrow$ holds promise to increase access to diagnostic services

$\begin{array}{ll}\begin{array}{l}\text { Acceptance, adherence and } \\ \text { completion of tuberculosis }\end{array} & \begin{array}{l}\text { Availability and use of shorter, 'patient-friendly', TPT regimens. This includes proper government } \\ \text { approval and procurement of rifapentine at price affordable to low-income persons }\end{array} \\ & \begin{array}{l}\text { Patient-centric motivational counselling, mHealth solutions (eg, SMS reminders), social support } \\ \text { and networking }\end{array} \\ & \begin{array}{l}\text { Treatment-positive messaging and training of all partners supporting TPT implementation. } \\ \text { Utilisation of ECHO platform for building a community of practice with regards to TPT }\end{array} \\ & \text { Programmatic reporting of TPT activities, including patient outcomes }\end{array}$

Monitoring treatment-related adverse events

Adopting treatment screening algorithms for the selection of treatment; screening for appropriate TPT exclusion criteria

Patient and provider education on TPT adverse events

Programmatic reporting of TPT activities, including patient outcomes

Availability and use of the national target spontaneous reporting pharmacovigilance system††

Procurement and supply chain Accurately estimating the burden of latent infection at subnational levels

management

National-level and state-level coordination and forecasting

Utilisation of Global Drug Facility technical assistance and procurement and supply management toolsł‡

Implementation research

Establishing a reliable, cost-effective test to rapidly detect tuberculosis infection, and identify those most likely to benefit from preventive treatment in the India context

Establishing TPT regimens that are most effective in India, with careful consideration of posology and duration for children and adults

Designing of effective, targeted, TPT interventions tailored to local epidemiology and programme performance

Assessing treatment cascades among persons with a high likelihood of progressing to active disease

Understanding transmission dynamics in a population with a high likelihood of repeated exposures

\footnotetext{
*United Nations, General Assembly. Draft resolution submitted by the President of the General Assembly. UN 72 Session. ${ }^{103}$ †Narendra Modi address at the End TB Summit. Delivered on March 13, 2018. ${ }^{104}$

$\ddagger$ Systematic Screening for Active Tuberculosis: Principles and Recommendations. Geneva: World Health Organization; $2013 .{ }^{105}$ $\S$ Central TB Division. TB India 2017: Revised national tuberculosis control program annual status report. New Delhi: Government of India; $2018 .^{90}$

ๆGovernment of India. Ayushman Bharat. ${ }^{106}$

${ }^{*}$ Struminger B, Arora S, Zalud-Cerrato S, Lowrance D, Ellerbrock T. Building virtual communities of practice for health. Lancet. 2017;390(10095):632-4. ${ }^{107}$

††Thota P, Thota A, Medhi B, et al. Drug safety alerts of pharmacovigilance programme of India: A scope for targeted spontaneous reporting in India. Perspect Clin Res. 2018 Jan-Mar;9(1):51-5. ${ }^{108}$

¥¥StopTB Partnership. Procurement and Supply Management (PSM) Tools. ${ }^{109}$

ECHO , Extension of Community Healthcare Outcomes; SMS, Short Message Service; TPT, Tuberculosis Preventive Treatment.
} 
Table 3 Guidelines for implementing a national tuberculosis preventive treatment programme in India

A recent review identified a number of further research needed to improve our understanding of tuberculosis infection from clinical and programmatic perspectives. ${ }^{93}$ Several priority activities may be adopted for India by thematic areas:

1. Accurate estimates of the tuberculosis infection burden in India. Rational, targeted testing and treatment of tuberculosis infection shall be guided by local epidemiological trends. This includes local and regional estimates for infection and also rates of antituberculosis drug resistance, diabetes mellitus, HIV coprevalence and undernutrition

2. Development and programmatic assessment of accurate diagnostic tests for predicting progression from infection to active tuberculosis disease. Tests should be sensitive and specific, convenient to the patient, inexpensive and highly reproducible. Ideally, tests should be able to distinguish between latency and active disease and recognise drugresistant forms of tuberculosis.

3. Improved selection of candidates for tuberculosis preventive treatment (TPT). We need to improve our understanding of the host-pathogen interaction in India, immunological response and biomarkers to predict which persons benefit most from TPT. We need further studies to understand how M. tuberculosis evades the immune system, which persons it infects, how it lays dormant for years and what mechanisms trigger progression to active disease. These studies will inform the development of vaccines and also which persons to treat.

4. Development and programmatic assessment of a variety of efficacious treatment options. Short, well-tolerated, therapeutic regimens are needed. Randomised clinical trials conducted in the Indian context to assess efficacy, tolerability and drug-interaction profile are required. In high prevalent areas, the risk of reinfection increases. In such communities, the optimal duration of treatment remains unclear. There is no evidence (through randomised clinical trial) of specific treatment regimens for persons exposed to drug-resistant forms of tuberculosis. We need further research to define the composition, posology and duration of preventive regimens for such persons.

5. Simple, easy-to-use algorithms for determining TPT eligibility, appropriate regimen and length of treatment should be developed based on individual risk, local epidemiology and programmatic performance.

6. Optimising tuberculosis infection treatment to the Indian context. Context-specific interventions need development to enhance adherence to treatment through the optimisation of local Indian resources

7. Monitoring and evaluation of programme performance in implementing tuberculosis infection treatment. Surveillance systems for tuberculosis infection and treatment-associated adverse events need to be developed and used to monitor programme implementation and performance. Preventive treatment cascades should be considered to objectively assess progress and make direct quantitative measurements of patient retention at each step of tuberculosis service delivery (figure 1).

8. Cost-effectiveness analysis. Targeted cost-effectiveness studies are required for the rational scale-up of tuberculosis infection treatment among various populations throughout India (eg, diabetics, undernourished and other vulnerable populations).

developed based on individual risk, local epidemiology and programmatic performance.

There remains a paucity of data for several programmatically relevant research questions within the Indian context. The Government of India, implementing partners, and stakeholders should consider addressing several, key operational research questions to inform policy and practice table $3{ }^{93}$ Implementation research focused on improved diagnostics to identify tuberculosis infection and effectively predict progression from infection to active disease; the performance and tolerability of shorter, adherence-friendly preventive regimens; optimal length of treatment (given potential risk of re-exposure); accurate estimates of local tuberculosis infection burden; improved mechanisms for monitoring programme performance and assessing cost effectiveness are top priorities. Research alone cannot stimulate change, however. Findings from these studies must be translated into sustainable policies that are adequately funded and effectively implemented in practice. The adoption of a standardised method of monitoring, such as the use of a tuberculosis prevention cascade (figure 1), may prove useful to objectively assess progress of the programmatic implementation of tuberculosis infection treatment. ${ }^{9495}$ There are many opportunities for losses in the continuum of care for tuberculosis infection diagnosis and treatment. ${ }^{9495}$ People with tuberculosis infection might not be identified for screening, and even if they are, many are not tested, or a test might be placed but results are not received by treating clinicians. Patients who test positive of tuberculosis infection may not be able to complete the required medical evaluation (eg, symptom review, chest radiograph), clinicians might opt not to initiate treatment (eg, lack of knowledge, drug intolerance, clinical contraindications) and patients may be unable to complete a full course of treatment. Prevention cascades can objectively identify these gaps, help develop strategies for effective interventions and offer opportunities to improve success. ${ }^{95}$ Cascades can also shift programme goals away from estimating coverage in the population served to making direct quantitative measurements of patient retention at each step of tuberculosis service delivery. ${ }^{96}$ Recent upgrades to the RNTCP web-based reporting system, NIKSHAY, ${ }^{97}$ may be a viable platform to develop and monitor district-level tuberculosis prevention cascades throughout India. 


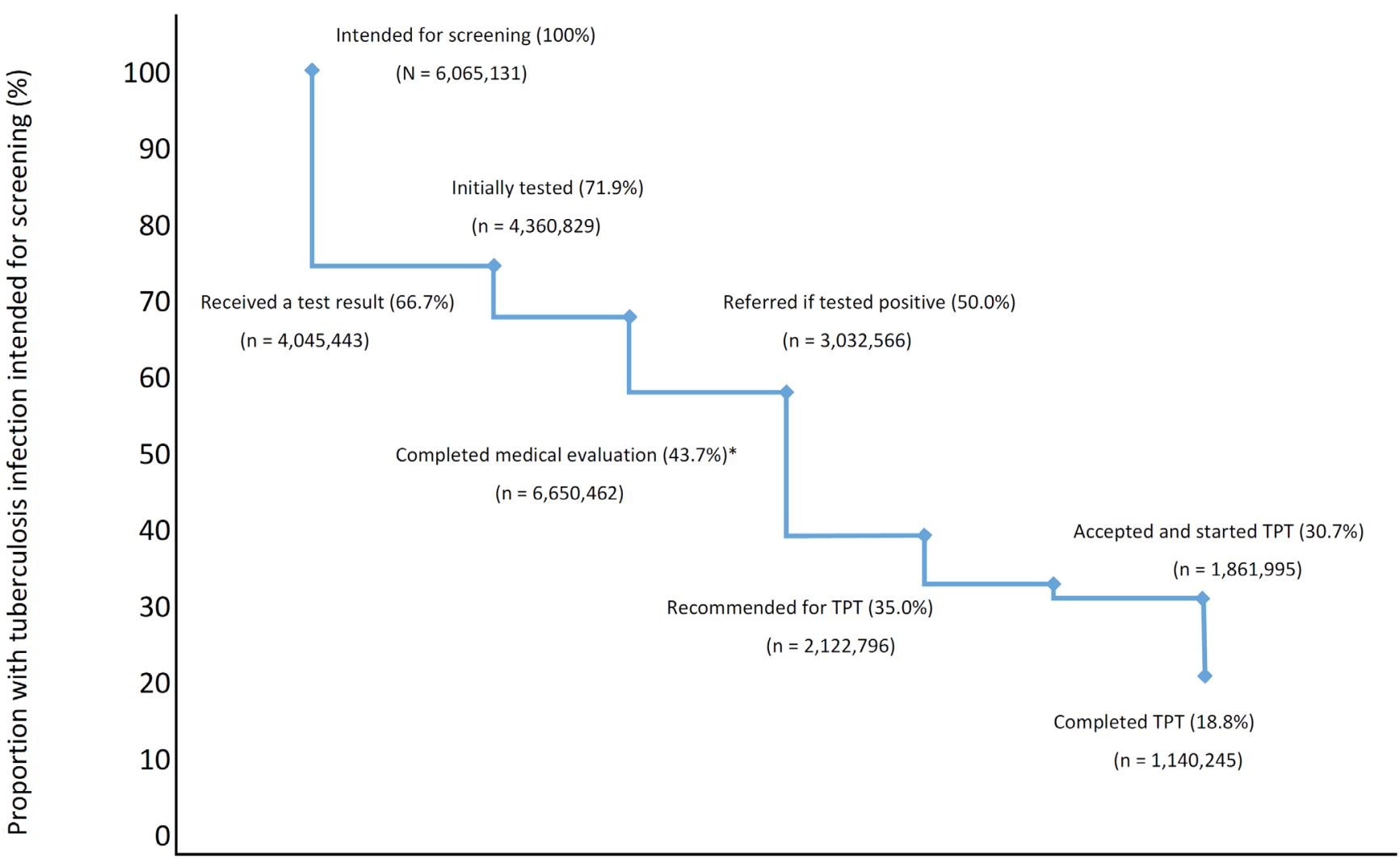

Figure 1 Potential losses at each stage of the TPT cascade. *Includes ruling out active tuberculosis. The values were based on the estimated number of household contacts exposed to pansensitive $M$. tuberculosis per year in India (table 1). Percentage lost at each stage was based on the meta-analysis of Alsdurf et al. ${ }^{95}$ TPT, tuberculosis preventive treatment.

India must address the major gaps previously identified in the cascade of care for TB disease ${ }^{98}$ and improve access and the quality of TB service delivery in the public, private and informal sectors ${ }^{99-101}$ prior to nationwide implementation of TPT. To achieve elimination, the national TB programme must take a phased multipronged approach to TB prevention and care. The first priority is continued progress to ensure early, accurate, tuberculosis diagnosis for all persons suffering from tuberculosis. All patients with tuberculosis must also be evaluated for antituberculosis drug resistance, placed on the most appropriate treatment regimen and properly managed and followed to treatment completion. In addition, simultaneous improvements to airborne infection control measures, contact tracing and targeted TPT for children and persons living with HIV must continue. The cascade of TPT among these groups should be thoroughly assessed. These data can inform a more effective implementation at each step of care. As access to quality TB diagnosis and care improves, antituberculosis treatment success rates increase, and TB incidence and prevalence decline and targeted TPT may be expanded to other high-risk groups.

\section{Conclusion}

Over the past decade, India has accomplished numerous impressive achievements in tuberculosis prevention, care and control. The RNTCP has screened more than 80 million people for tuberculosis, successfully treated 15 million patients and saved millions of lives. ${ }^{102}$ Leading by example, India can contribute to the global knowledge of TPT through research and programmatic implementation. The next chapter in tuberculosis elimination in India will require evidence-based, cost-effective and sustainable interventions. TPT will play a major role in bending the epidemiological curve in India. This will require constant innovation, locally driven solutions, and persistent programme monitoring and evaluation to address the diverse and dynamic tuberculosis epidemiology. As new tools, regimens and approaches emerge, midcourse adjustments to policy and practice must be quickly adopted and sufficiently resourced. The development and implementation of new tools and strategies will call for close collaboration between local, national and international partners-both public and privatenational health authorities, non-governmental organisations, research community and the diagnostic and pharmaceutical industry. Together our collective effort will end tuberculosis in our lifetime.

\section{Author affiliations}

${ }^{1}$ Global Tuberculosis Branch, U.S. Centers for Disease Control and Prevention, Atlanta, Georgia, USA

${ }^{2}$ Stop TB Partnership, Geneva, Switzerland

${ }^{3} \mathrm{CDC}$ India Country Office, U.S. Centers for Disease Control and Prevention, New Delhi, India

${ }^{4}$ Department of Epidemiology and Research, National Tuberculosis Institute, Bangalore, India 
${ }^{5}$ Global Health, Bill and Melinda Gates Foundation, Seattle, USA

${ }^{6}$ National JALMA Institute for Leprosy and other Mycobacterial Diseases, Agra, India ${ }^{7}$ Department of Research, International Union Against Tuberculosis and Lung Disease, Paris, France

${ }^{8}$ Revised National Tuberculosis Control Programme, India Ministry of Health and Family Welfare, New Delhi, India

${ }^{9}$ National Tuberculosis Institute, Bangalore, India

${ }^{10}$ WHO India Country Office, World Health Organization, New Delhi, India

${ }^{11}$ India Country Office, Foundation for Innovative New Diagnostics, New Delhi, India

${ }^{12}$ India Country Office, World Health Organization, New Delhi, India

${ }^{13}$ National Institute of Tuberculosis and Respiratory Diseases, New Delhi, India

${ }^{14}$ Department of Epidemiology, National Institute for Research in Tuberculosis, Chennai, India

${ }^{15}$ Department of Tuberculosis and Respiratory Diseases, National Institute of Tuberculosis and Respiratory Diseases, New Delhi, India

${ }^{16}$ South-east Asia Office, International Union Against Tuberculosis and Lung

Disease, New Delhi, India

${ }^{17}$ National Institute for Research in Tuberculosis, Chennai, India

Contributors PKM and SAN conceived, designed and drafted the initial manuscript. PKM, VKC, JEO acquired and analysed the data. RA, CH, THH and DS provided technical support to interpreting the results. RA, VKC, PD, UDG, CH, THH, AK, NK, PK, SAM, SRM, JEO, CNP, MMP, KKR, RR, RR, VSS, RS, SS, KSS, SS, RS, DS, JT, SPT and SDK revised the initial draft and provided critically important intellectual content. PKM and SAN integrated all feedback and investigated and resolved any questions from internal and required clearance at $\mathrm{CDC}$ and WHO prior to publication. SDK provided overall leadership and oversight. All authors attest to the accuracy and integrity of final version.

Funding This study was funded in part by U.S. President's Emergency Plan for AIDS Relief.

Competing interests None declared.

Patient consent Not required.

Provenance and peer review Not commissioned; externally peer reviewed.

Data sharing statement Unless otherwised stated, all data presented are in the public domain and freely avaialble for use.

Open access This is an open access article distributed in accordance with the Creative Commons Attribution Non Commercial (CC BY-NC 4.0) license, which permits others to distribute, remix, adapt, build upon this work non-commercially, and license their derivative works on different terms, provided the original work is properly cited, appropriate credit is given, any changes made indicated, and the use is non-commercial. See: http://creativecommons.org/licenses/by-nc/4.0/

\section{REFERENCES}

1. World Health Organization 67th World Health Assembly. Global strategy and targets for tuberculosis prevention, care and control after 2015. A67/11. Geneva: World Health Organization, 2014

2. Uplekar M, Weil D, Lonnroth K, et al. WHO's new end TB strategy. Lancet 2015;385:1799-801.

3. Raviglione MC, Ditiu L. Setting new targets in the fight against tuberculosis. Nat Med 2013;19:263.

4. Lönnroth K, Migliori GB, Abubakar I, et al. Towards tuberculosis elimination: an action framework for low-incidence countries. Eur Respir J 2015;45:928-52.

5. LoBue PA, Mermin JH. Latent tuberculosis infection: the final frontier of tuberculosis elimination in the USA. Lancet Infect Dis 2017;17:e327-e333.

6. Nnadi CD, Anderson LF, Armstrong LR, et al. Mind the gap: TB trends in the USA and the UK, 2000-2011. Thorax 2016;71:356-63.

7. Ricks PM, Cain KP, Oeltmann JE, et al. Estimating the burden of tuberculosis among foreign-born persons acquired prior to entering the U.S., 2005-2009. PLoS One 2011;6:e27405.

8. Aldridge RW, Zenner D, White PJ, et al. Tuberculosis in migrants moving from high-incidence to low-incidence countries: a population-based cohort study of 519955 migrants screened before entry to England, Wales, and Northern Ireland. Lancet 2016:388:2510-8.

9. World Health Organization, 2018. The end TB strategy. Available from: http://www.who.int/tb/post2015 strategy/en/ [accessed 6 Sep 2018].
10. Houben RM, Dodd PJ. The global burden of latent tuberculosis infection: a re-estimation using mathematical modelling. PLoS Med 2016;13:e1002152

11. Zorini AO. On a new method of antituberculosis chemioprophylaxis employing isonicotinic acid hydrazide. Sci Med Ital 1957;6:37-47.

12. Comstock GW. Isoniazid prophylaxis in an undeveloped area. $A m$ Rev Respir Dis 1962;80:810-22.

13. Ferebee $\mathrm{SH}$. Controlled chemoprophylaxis trials in tuberculosis. $\mathrm{A}$ general review. Bibl Tuberc 1970;26:28-106.

14. Comstock GW, Baum C, Snider DE. Isoniazid prophylaxis among Alaskan Eskimos: a final report of the bethel isoniazid studies. Am Rev Respir Dis 1979;119:827-30.

15. Grzybowski S, Styblo K, Dorken E. Tuberculosis in Eskimos. Tubercle 1976;57(4 Suppl):S1-S58.

16. Lobue P, Menzies D. Treatment of latent tuberculosis infection: An update. Respirology 2010;15:603-22.

17. Sterling TR, Villarino ME, Borisov AS, et al. Three months of rifapentine and isoniazid for latent tuberculosis infection. $N$ Engl J Med 2011;365:2155-66.

18. Diel R, Loddenkemper R, Zellweger JP, et al. Old ideas to innovate tuberculosis control: preventive treatment to achieve elimination. Eur Respir J 2013;42:785-801.

19. Reichman LB. The tuberculosis taboo. Int J Tuberc Lung Dis 2017;21:251-5.

20. World Health Organization. Global tuberculosis report, 2016. Geneva: World Health Organization, 2016.

21. Arinaminpathy N, Batra D, Khaparde S, et al. The number of privately treated tuberculosis cases in India: an estimation from drug sales data. Lancet Infect Dis 2016;16:1255-60.

22. Pai M, Bhaumik S, Bhuyan SS. India's plan to eliminate tuberculosis by 2025: converting rhetoric into reality. BMJ Glob Health 2016;2:e000326.

23. Revised National Tuberculosis Control Programme. National strategic plan for tuberculosis elimination, 2017: 25.

24. Houben R, Menzies NA, Sumner T, et al. Feasibility of achieving the 2025 WHO global tuberculosis targets in South Africa, China, and India: a combined analysis of 11 mathematical models. Lancet Glob Health 2016;4:e806-e815.

25. Nair D, Rajshekhar N, Klinton JS, et al. Household contact screening and yield of tuberculosis cases-a clinic based study in Chennai, South India. PLoS One 2016;11:e0162090.

26. Khaparde K, Jethani P, Dewan PK, et al. Evaluation of TB Case Finding through Systematic Contact Investigation, Chhattisgarh, India. Tuberc Res Treat 2015;2015:670167.

27. Narasimhan $P$, Maclntyre CR, Mathai D, et al. High rates of latent TB infection in contacts and the wider community in South India. Trans R Soc Trop Med Hyg 2017;111:55-61.

28. Sharma SK, Vashishtha R, Chauhan LS, et al. Comparison of TST and IGRA in Diagnosis of Latent Tuberculosis Infection in a High TB-Burden Setting. PLoS One 2017;12:e0169539.

29. Singh J, Sankar MM, Kumar S, et al. Incidence and prevalence of tuberculosis among household contacts of pulmonary tuberculosis patients in a peri-urban population of South Delhi, India. PLoS One 2013;8:e69730.

30. Revised National Tuberculosis Control Programme, 2017. Annual Status Report, 2017. Available from: https://tbcindia.gov.in/ WriteReadData/TB\%20India\%202017.pdf [accessed 6 Sep 2018]

31. Office of the Registrar General and Census Commissioner, India, 2018. HH-01. Normal households by household size. Available from: http://www.censusindia.gov.in/2011census/hh-series/hh01. html [accessed 6 Sep 2018]

32. Salgame P, Geadas C, Collins L, et al. Latent tuberculosis infection-Revisiting and revising concepts. Tuberculosis 2015;95:373-84.

33. Trauer JM, Moyo N, Tay EL, et al. Risk of active tuberculosis in the five years following infection ... 15\%? Chest 2016;149:516-25.

34. Zachariah R, Spielmann MP, Harries AD, et al. Passive versus active tuberculosis case finding and isoniazid preventive therapy among household contacts in a rural district of Malawi. Int J Tuberc Lung Dis 2003;7:1033-9.

35. Jensen PA, Lambert LA, lademarco MF, et al. Guidelines for preventing the transmission of Mycobacterium tuberculosis in health-care settings, 2005. MMWR Recomm Rep 2005;54(RR17):1-141.

36. Parmar MM, Sachdeva KS, Rade K, et al. Airborne infection control in India: Baseline assessment of health facilities. Indian J Tuberc 2015;62:211-7.

37. Baussano I, Nunn P, Williams B, et al. Tuberculosis among health care workers. Emerg Infect Dis 2011;17:488-94.

38. Barrera E, Livchits V, Nardell E. F-A-S-T: a refocused, intensified, administrative tuberculosis transmission control strategy. Int $J$ Tuberc Lung Dis 2015;19:381-4. 
39. Revised National Tuberculosis Control Programme. Technical and Operational Guidelines for TB Control in India, 2016.

40. Watkins RE, Brennan R, Plant AJ. Tuberculin reactivity and the risk of tuberculosis: a review. Int J Tuberc Lung Dis 2000;4:895-903.

41. Pai M, Denkinger CM, Kik SV, et al. Gamma interferon release assays for detection of Mycobacterium tuberculosis infection. Clin Microbiol Rev 2014;27:3-20.

42. Metcalfe JZ, Everett CK, Steingart KR, et al. Interferon- $\gamma$ release assays for active pulmonary tuberculosis diagnosis in adults in low- and middle-income countries: systematic review and metaanalysis. J Infect Dis 2011;204 Suppl 4:S1120-S1129.

43. Sester M, Sotgiu G, Lange C, et al. Interferon- $\gamma$ release assays for the diagnosis of active tuberculosis: a systematic review and metaanalysis. Eur Respir J 2011;37:100-11.

44. Herrera V, Perry S, Parsonnet J, et al. Clinical application and limitations of interferon-gamma release assays for the diagnosis of latent tuberculosis infection. Clin Infect Dis 2011;52:1031-7.

45. Powell RD, Whitworth WC, Bernardo J, et al. Unusual interferon gamma measurements with QuantiFERON-TB Gold and QuantiFERON-TB Gold In-Tube tests. PLoS One 2011;6:e20061.

46. Metcalfe JZ, Cattamanchi A, McCulloch CE, et al. Test variability of the QuantiFERON-TB gold in-tube assay in clinical practice. Am J Respir Crit Care Med 2013;187:206-11.

47. Whitworth WC, Hamilton LR, Goodwin DJ, et al. Within-subject interlaboratory variability of QuantiFERON-TB gold in-tube tests. PLoS One 2012;7:e43790.

48. Nienhaus A, Schablon A, Costa JT, et al. Systematic review of cost and cost-effectiveness of different TB-screening strategies. BMC Health Serv Res 2011:11:247.

49. Oxlade O, Pinto M, Trajman A, et al. How methodologic differences affect results of economic analyses: a systematic review of interferon gamma release assays for the diagnosis of LTBI. PLOS One 2013;8:e56044.

50. World Health Organization. Commercial serodiagnostic tests for diagnosis of tuberculosis: policy statement. Geneva: World Health Organization, 2011.

51. Kumar A, 2011. Advisory against commercial serological tests. New Delhi: Central TB Division, Ministry of Health and Family Welfare; 2011. Directorate General of Health Services. Available from: http:// www.tbcindia.nic.in/pdfs/Letter_Serodiagnosis.pdf

52. Jarosławski S, Pai M. Why are inaccurate tuberculosis serological tests widely used in the Indian private healthcare sector? A rootcause analysis. J Epidemiol Glob Health 2012;2:39-50.

53. Tebruegge M, Bogyi M, Soriano-Arandes A, et al. Shortage of purified protein derivative for tuberculosis testing. Lancet 2014;384:384.

54. Joint Monitoring Mission, India, 2015. Report of the Joint Monitoring Mission India. Available from: http://www.tbonline.info/ media/uploads/documents/jmmdraft2015.pdf [accessed 22 Aug 2017].

55. Pothukuchi M, Nagaraja SB, Kelamane S, et al. Tuberculosis contact screening and isoniazid preventive therapy in a South Indian district: operational issues for programmatic consideration. PLoS One 2011;6:e22500.

56. Banu Rekha VV, Jagarajamma K, Wares F, et al. Contact screening and chemoprophylaxis in India's Revised Tuberculosis Control Programme: a situational analysis. Int $J$ Tuberc Lung Dis 2009;13:1507-12.

57. Shivaramakrishna HR, Frederick A, Shazia A, et al. Isoniazid preventive treatment in children in two districts of South India: does practice follow policy? Int J Tuberc Lung Dis 2014;18:919-24.

58. Singh AR, Kharate A, Bhat P, et al. Isoniazid Preventive Therapy among Children Living with Tuberculosis Patients: Is It Working? A Mixed-Method Study from Bhopal, India. J Trop Pediatr 2017;63:274-85.

59. Pathak RR, Mishra BK, Moonan PK, et al. Can intensified tuberculosis case finding efforts at nutrition rehabilitation centers lead to pediatric case detection in Bihar, India? J Tuberc Res 2016;4:46-54.

60. Pai M, Gokhale K, Joshi R, et al. Mycobacterium tuberculosis infection in health care workers in rural India: comparison of a whole-blood interferon gamma assay with tuberculin skin testing. JAMA 2005;293:2746-55.

61. Christopher DJ, Daley P, Armstrong L, et al. Tuberculosis infection among young nursing trainees in South India. PLoS One 2010;5:e10408.

62. Kopanoff DE, Snider DE, Caras GJ. Isoniazid-related hepatitis: a U.S. Public Health Service cooperative surveillance study. Am Rev Respir Dis 1978;117:991-1001.
63. Nolan CM, Goldberg SV, Buskin SE. Hepatotoxicity associated with isoniazid preventive therapy: a 7-year survey from a public health tuberculosis clinic. JAMA 1999;281:1014-8.

64. Denholm JT, McBryde ES, Eisen DP, et al. Adverse effects of isoniazid preventative therapy for latent tuberculosis infection: a prospective cohort study. Drug Healthc Patient Saf 2014;6:145-9.

65. Samandari T, Agizew TB, Nyirenda S, et al. 6-month versus 36-month isoniazid preventive treatment for tuberculosis in adults with HIV infection in Botswana: a randomised, double-blind, placebo-controlled trial. Lancet 2011;377:1588-98.

66. Martinson NA, Barnes GL, Moulton LH, et al. New regimens to prevent tuberculosis in adults with HIV infection. N Engl J Med 2011;365:11-20.

67. Swaminathan S, Menon PA, Gopalan N, et al. Efficacy of a sixmonth versus a 36-month regimen for prevention of tuberculosis in HIV-infected persons in India: a randomized clinical trial. PLoS One 2012;7:e47400.

68. Sandul AL, Nwana N, Holcombe JM, et al. High rate of treatment completion in program settings with 12-dose weekly isoniazid and rifapentine for latent Mycobacterium tuberculosis infection. Clin Infect Dis 2017;65:1085-93.

69. Pease C, Hutton B, Yazdi F, et al. Efficacy and completion rates of rifapentine and isoniazid (3HP) compared to other treatment regimens for latent tuberculosis infection: a systematic review with network meta-analyses. BMC Infect Dis 2017;17:265.

70. Ministry of Health and Family Welfare. Government of India. Report of the first nationwide antituberculosis drug resistance survey India, 2014 - 2015. Revised National Tuberculosis Programme, 2018.

71. American Thoracic SocietyCenters for Disease Control and Prevention. Targeted tuberculin testing and treatment of latent tuberculosis infection. Am J Respir Crit Care Med 2000;161(supp lement 3):S221-S247.

72. Polesky A, Farber HW, Gottlieb DJ, et al. Rifampin preventive therapy for tuberculosis in Boston's homeless. Am J Respir Crit Care Med 1996;154:1473-7.

73. Villarino ME, Ridzon R, Weismuller PC, et al. Rifampin preventive therapy for tuberculosis infection: experience with 157 adolescents. Am J Respir Crit Care Med 1997;155:1735-8.

74. Bamrah S, Brostrom R, Dorina F, et al. Treatment for LTBI in contacts of MDR-TB patients, Federated States of Micronesia, 2009-2012. Int J Tuberc Lung Dis 2014;18:912-8.

75. World Health Organization. WHO treatment guidelines for rifampicin- and multidrug-resistant tuberculosis, 2018 update. WHO 2018. Available from: http://www.who.int/tb/areas-of-work/ drug-resistant-tb/treatment/gdg-meeting-mdr-rr-tb-treatment2018-update/en/ [accessed 6 Sep 2018].

76. van der Werf MJ, Langendam MW, Sandgren A, et al. Lack of evidence to support policy development for management of contacts of multidrug-resistant tuberculosis patients: two systematic reviews. Int J Tuberc Lung Dis 2012;16:288-96.

77. Kotwani A, Holloway K. Trends in antibiotic use among outpatients in New Delhi, India. BMC Infect Dis 2011;11:99.

78. Satyanarayana S, Kwan A, Daniels B, et al. Use of standardised patients to assess antibiotic dispensing for tuberculosis by pharmacies in urban India: a cross-sectional study. Lancet Infect Dis 2016;16:1261-8.

79. Kotwani A, Wattal C, Joshi PC, et al. Irrational use of antibiotics and role of the pharmacist: an insight from a qualitative study in New Delhi, India. J Clin Pharm Ther 2012;37:308-12.

80. Landstedt K, Sharma A, Johansson F, et al. Antibiotic prescriptions for inpatients having non-bacterial diagnosis at medicine departments of two private sector hospitals in Madhya Pradesh, India: a cross-sectional study. BMJ Open 2017;7:e012974.

81. Matteelli A, Rendon A, Tiberi S, et al. Tuberculosis elimination: where are we now? Eur Respir Rev 2018;27:180035.

82. Rao VG, Bhat J, Yadav R, et al. Prevalence of pulmonary tuberculosis--a baseline survey in central India. PLoS One 2012;7:e43225

83. Chadha VK, Kumar P, Anjinappa SM, et al. Prevalence of pulmonary tuberculosis among adults in a rural sub-district of South India. PLoS One 2012;7:e42625.

84. Katoch K, Chauhan DS, Yadav VK, et al. Prevalence survey of bacillary pulmonary tuberculosis in Western Uttar Pradesh, India. $J$ Infect Pulm Dis 2015;1:1-7.

85. Narang P, Mendiratta DK, Tyagi NK, et al. Prevalence of pulmonary tuberculosis in Wardha district of Maharashtra, Central India. $J$ Epidemiol Glob Health 2015;5(4 Suppl 1):S11-S18.

86. Sharma SK, Goel A, Gupta SK, et al. Prevalence of tuberculosis in Faridabad district, Haryana State, India. Indian J Med Res 2015;141:228-35. 
87. Dhanaraj B, Papanna MK, Adinarayanan S, et al. Prevalence and risk factors for adult pulmonary tuberculosis in a metropolitan city of South India. PLoS One 2015;10:e0124260.

88. Chadha VK, Sarin R, Narang P, et al. Trends in the annual risk of tuberculous infection in India. Int J Tuberc Lung Dis 2013;17:312-9.

89. Chadha VK. Tuberculosis epidemiology in India: a review. Int $J$ Tuberc Lung Dis 2005;9:1072-82.

90. Central TB Division. TB India 2017: Revised national tuberculosis control program annual status report. New Delhi: Government of India, 2018.

91. Pandey S, Chadha VK, Laxminarayan R, et al. Estimating tuberculosis incidence from primary survey data: a mathematical modeling approach. Int J Tuberc Lung Dis 2017;21:366-74.

92. Balcells ME, Thomas SL, Godfrey-Faussett P, et al. Isoniazid preventive therapy and risk for resistant tuberculosis. Emerg Infect Dis 2006;12:744-51.

93. World Health Organization, 2017. LTBI Research. Available from: http://www.who.int/tb/areas-of-work/preventive-care/ltbi_research/ en/ [Accessed 30 Aug 2017].

94. Dheda K. Getting bang for buck in the latent tuberculosis care cascade. Lancet Infect Dis 2016;16:1209-10.

95. Alsdurf $\mathrm{H}$, Hill PC, Matteelli A, et al. The cascade of care in diagnosis and treatment of latent tuberculosis infection: a systematic review and meta-analysis. Lancet Infect Dis 2016;16:1269-78.

96. Cazabon D, Alsdurf H, Satyanarayana S, et al. Quality of tuberculosis care in high burden countries: the urgent need to address gaps in the care cascade. Int J Infect Dis 2017;56:111-6.

97. Revised National Tuberculosis Control Programme. Government of India. Available from: http://nikshay.gov.in [accessed 6 Sept 2017].

98. Subbaraman R, Nathavitharana RR, Satyanarayana S, et al. The tuberculosis cascade of care in India's public sector: recent estimates and gaps in knowledge. PLoS Med 2016;13:e1002149.
99. Sreeramareddy CT, Qin ZZ, Satyanarayana S, et al. Delays in diagnosis and treatment of pulmonary tuberculosis in India: a systematic review. Int J Tuberc Lung Dis 2014;18:255-66.

100. Das J, Kwan A, Daniels B, et al. Use of standardised patients to assess quality of tuberculosis care: a pilot, cross-sectional study. Lancet Infect Dis 2015;15:1305-13.

101. McDowell A, Pai M. Treatment as diagnosis and diagnosis as treatment: empirical management of presumptive tuberculosis in India. Int J Tuberc Lung Dis 2016;20:536-43.

102. Mandal S, Chadha VK, Laxminarayan R, et al. Counting the lives saved by DOTS in India: a model-based approach. BMC Med 2017;15:47.

103. United Nations, General Assembly, 2018. Draft resolution submitted by the president of the gerneral assembly. UN 72 Session. Available from: http://undocs.org/en/A/72/L.40 [accessed 18 June 2018].

104. Office of the Prime Minister of India, 2018. Narendra modi address at the end TB summit. Available from: https://www.narendramodi. in/text-of-pm-s-address-at-the-inaugural-session-of-end-tbsummit-539297 [Accessed 18 June 2018].

105. World Health Organization. Systematic Screening for Active Tuberculosis: Principles and Recommendations. Geneva: World Health Organization, 2013.

106. Government of India. Ayushman Bharat. Available from: https:// www.india.gov.in/spotlight/ayushman-bharat-national-healthprotection-mission [accessed 18 June 2018].

107. Struminger B, Arora S, Zalud-Cerrato S, et al. Building virtual communities of practice for health. Lancet 2017;390:632-4.

108. Thota P, Thota A, Medhi B, et al. Drug safety alerts of pharmacovigilance programme of India: a scope for targeted spontaneous reporting in India. Perspect Clin Res 2018;9:51-5.

109. StopTB Partnership, 2016. Procurement and Supply Management (PSM) Tools. Available from: http://www.stoptb.org/gdf/drugsupply/ psmtools.asp [Accessed 18 Jun 2018]. 